where

$$
F_{(n+1) !}=S_{n+1}\left(F_{n !}\right)\left[C\left(f_{n+1}(x)\right)\right]
$$

and $C\left(f_{n+1}(x)\right)$ in $\left(F_{n !}\right)_{n+1}$ is the companion matrix of $f_{n+1}(x)$. Remembering the natural isomorphism between $\left(K_{n !}\right)_{n+1}$ and $(K)_{(n+1)}$ ! for arbitrary fields $K$, we see that $\operatorname{GF}\left(p^{(n+1) !}\right)$ is a subfield of $(\mathrm{GF}(p))_{\infty}$ and has order $p^{(n+1) !}$. Furthermore, $\mathrm{GF}\left(p^{1 !}\right) \subset \cdots \subset \mathrm{GF}\left(p^{n !}\right) \subset \mathrm{GF}\left(p^{(n+1) !}\right)$. We define $\mathrm{GF}\left(p^{\infty !}\right)=$ $\bigcup_{n=1}^{\infty} \mathrm{GF}\left(p^{n !}\right)$ and are done.

Department of Mathematics

The University of Texas at Arlington

Arlington, Texas 76019

1. A. A. ALBERT, Fundamental Concepts of Higher Algebra, Univ. of Chicago Press, Chicago, Ill., 1958. MR 20 \#5190.

2. J. T. B. BEARD, JR., "Matrix fields over prime fields," Duke Math. J., v. 39, 1972, pp. 313-322.

3. E. R. BERKLEKAMP, "Factoring polynomials over large finite fields," Math. Comp., v. 24, 1970, pp. 713-735. MR 34 \#1948.

4. E. R. BERLEKAMP, Algebraic Coding Theory, McGraw-Hill, New York, 1968. MR 38 \#6873.

5. L. CARLITZ, "Primitive roots in a finite field," Trans. Amer. Math. Soc., v. 73, 1952, pp. 373-382. MR 14, 539.

6. H. DAVENPORT, “Bases for finite fields," J. London Math. Soc., v. 43, 1968, pp. 21-39; ibid., v. 44, 1969, p. 378. MR 37\#2729; 38 \#2127.

7. O. ORE, "Contributions to the theory of finite fields," Trans. Amer. Math. Soc., v. 36, 1934, pp. 243-274.

\title{
Some Primitive Polynomials of the Third Kind
}

\section{By Jacob T. B. Beard, Jr. ${ }^{*}$ and Karen I. West}

Abstract. This paper gives the first primitive polynomial of the third kind of degree $n$ over $\mathrm{GF}\left(p^{d}\right)$ for each $p, d, n$ satisfying $p<10^{2}, p^{d}<10^{3}, p^{d n}<10^{6}$.

In the preceding paper [1, Section 3] Beard introduced an exponential representation for $\mathrm{GF}\left(p^{d}\right)$ which allows full use of its multiplicative structure and permits direct rational calculations in $\mathrm{GF}\left(p^{d}\right)$. As indicated in [1, Section 4], such representations are easily and quickly obtained once primitive polynomials of the third kind of degree $d$

Received May 14, 1973:

AMS (MOS) subject classifications (1970). Primary 12-04, 12C05, $12 \mathrm{C} 15$.

Key words and phrases. Arithmetic in finite fields, primitive polynomials.

* This author was partially supported by the University of Texas Graduate Development Program and Organized Research Grants. 
over $\mathrm{GF}(p)$ are known. More generally, in this paper the authors give a primitive polynomial of the third kind of degree $n$ over $\mathrm{GF}\left(p^{d}\right)$ for each $p, d, n$ satisfying $p<10^{2}$, $p^{d}<10^{3}, p^{d n}<10^{6}$. Each $\mathrm{GF}\left(p^{d}\right)$ is the exponential representation of [1, Section 3] as defined by the polynomial given here of degree $d$ over $\operatorname{GF}(p)$. Under the natural lexicographic order on GF $\left[p^{d}, x\right]$, each of these polynomials is the first primitive polynomial of the third kind of its degree over $\operatorname{GF}\left(p^{d}\right)$. They were obtained through a search option in a software package developed by the authors and based on techniques described in [1]. Exhaustive tables of prime polynomials and the three kinds of primitive polynomials have been compiled for the smaller cases and degrees, portions of which will appear in due time. Those given in this paper are to be found on a microfiche card at the back of this journal.

The authors are indebted to the staff of the University Computer Center for their continuing cooperation and assistance. Particular thanks are extended to the Director, Melvin L. Pierce, and to Thomas R. Kennedy.

Department of Mathematics

The University of Texas at Arlington

Arlington, Texas 76019

1. J. T. B. BEARD, JR., “Computing in GF(q)," Math. Comp., v. 28, 1974, pp. 1159-1166.

\title{
Factorization Tables for $x^{n}-1 \operatorname{Over} G F(q)$
}

\author{
By Jacob T. B. Beard, Jr.* and Karen I. West
}

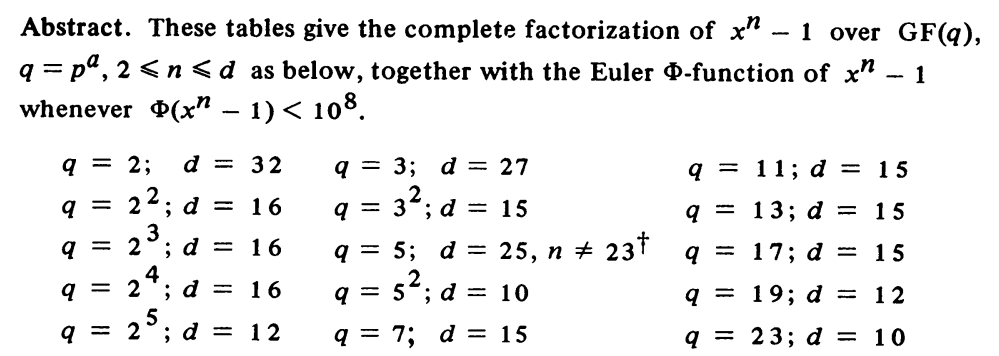

This paper gives the complete factorization of $x^{n}-1$ over $\operatorname{GF}(q), q=p^{a}$, as indi-

Received October 11, 1973.

AMS (MOS) subject classifications (1970). Primary 12C05, 12C30. Secondary $12 \mathrm{E} 05$.

Key words and phrases. Factorization, Galois field, Euler $\Phi$-function.

*This author was partially supported by an Organized Research Grant from the University of Texas at Arlington.

$\dagger$ Added at galley by the authors. $\left(x^{23}-1\right) /(x-1)$ is prime in $\mathrm{GF}[5, x]$ by 33. Theorem in Dickson's Linear Groups. 